\section{(อ)} OPEN ACCESS

\title{
Incidental finding of MEN-1 syndrome during staging and follow-up of breast carcinoma
}

\author{
Bernardo Conde Maria (10 , Ana Catarina Quadros, ${ }^{2}$ Natália Alves, ${ }^{1}$ João Coutinho
}

${ }^{1}$ Surgery, Centro Hospitalar Lisboa Norte EPE, Lisboa, Portugal

2Pathology, Centro Hospitalar Lisboa Norte EPE, Lisboa, Portugal

Correspondence to Dr Bernardo Conde Maria; bmaria_4@hotmail.com

Accepted 25 November 2020

\section{SUMMARY}

Type 1 multiple endocrine neoplasia (MEN-1) syndrome is an autosomal dominant disease, associated with germline mutations in the MEN-1 tumour suppressor gene (encoding the menin protein). Recent studies, through a better characterisation of the functions of the menin protein, have started to demonstrate how changes in this protein may be related to breast cancer. We present the case of a patient whose diagnosis of MEN-1 syndrome was made during treatment for a breast tumour - this diagnosis was obtained after finding multiple neoplastic lesions that fitted the MEN1 syndrome spectrum, during the initial staging and subsequent follow-up of a breast tumour. In line with the growing evidence that links MEN-1 syndrome to breast cancer tumorigenesis, this case report highlights the following question: should we start screening this subset of patients earlier for breast cancer?

\section{BACKGROUND}

Type 1 multiple endocrine neoplasia (MEN-1) syndrome is an autosomal dominant disease, associated with germline mutations in the MEN-1 tumour suppressor gene (encoding the menin protein) and characterised by parathyroid adenomas, duodenopancreatic neuroendocrine tumours (NETs) and pituitary tumours. ${ }^{1}$ The most common pathological entity in these patients is parathyroid adenoma with resulting primary hyperparathyroidism (95\%), followed by pancreatic NETs (gastrinomas, insulinomas, glucagonomas and non-functional NETs$40 \%-70 \%$ ) and anterior pituitary tumours. ${ }^{2}$

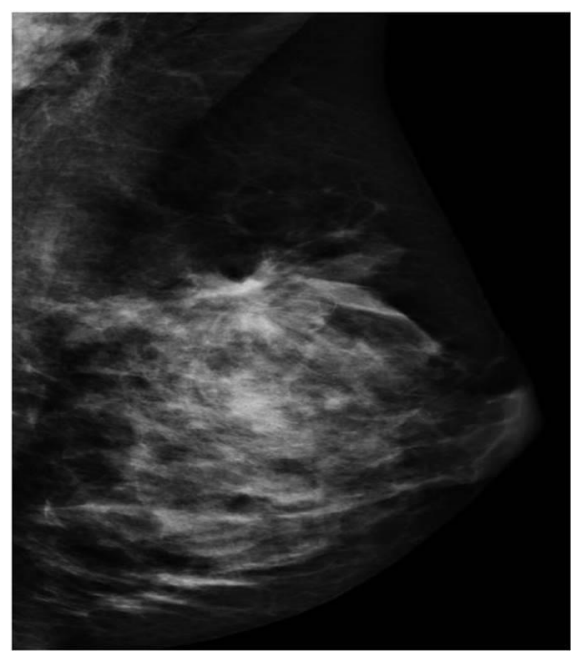

Figure 1 Mammography-nodular area in the upperinternal quadrant of the left breast.

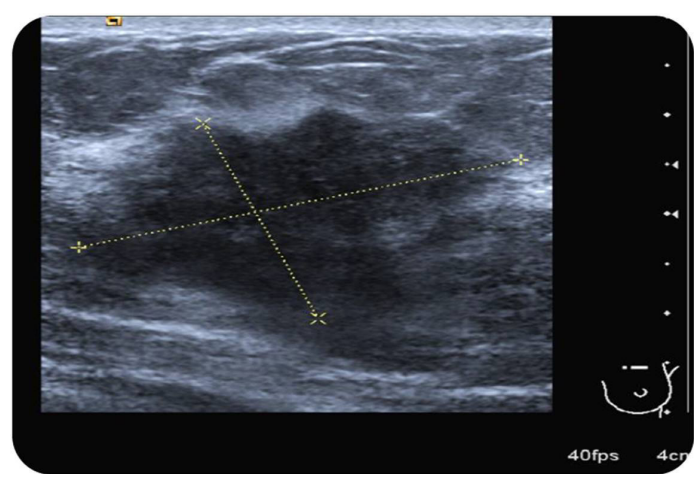

Figure 2 Breast ultrasound $-33 \times 21.3 \mathrm{~mm}$ nodular area in the upper-internal quadrant of the left breast.

The functions of the menin protein have been related to the regulation of gene transcription and chromatin modification-through its interaction with histone methyltransferase complexes, ${ }^{3}$ by binding to the promoter regions of various genes and regulating their expression ${ }^{4}$ and through their correlation with cyclin-dependent kinase inhibitors. ${ }^{5}$ Thus, it may be involved in controlling cell proliferation by its regulatory role in the transcription of genes involved in cell cycle progression. ${ }^{1}$ There is also evidence that it plays an important role in responding to exogenous DNA damage by disrupting the cell cycle in the $S$ phase. ${ }^{6}$ All of this knowledge about the MEN-1 gene suggests multiple possible cellular mechanisms through which its mutations may lead to oncogenesis. ${ }^{1}$

Although, until recently, only a few clinical cases have described a relationship of this syndrome with the development of breast tumours, ${ }^{7}$ a growing number of recent studies, through a better characterisation of the functions of the menin protein,

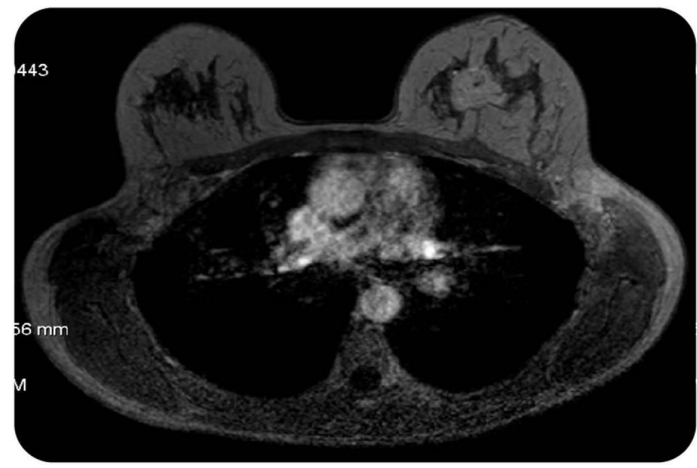

Figure 3 Breast MRI, T1-weighted—nodular area of $30 \times 25 \mathrm{~mm}$ with irregular morphology and borders and heterogeneous contrast enhancement. 
have started to demonstrate how changes in this protein may potentiate this type of cancer.

An animal model study demonstrated an increase in mammary intraepithelial neoplasia in mice with MEN-1 gene inactivation ${ }^{8}$; other studies have demonstrated the relationship of the menin protein with the oestrogen alpha receptor and how it may be a direct coactivator of this receptor-mediated gene transcription in mammary tumour cells. ${ }^{9} 10$ Through this latter function in the regulation of oestrogen receptor-mediated transcription, menin influences TFF1 (trefoil factor 1) protein levels-TFF1 levels are shown to be increased and positively related to estrogen-positive breast tumours, ${ }^{11}$ and TFF1 expression is reduced or null in normal breast tissue. ${ }^{12}$

The Dutch MEN1 Study Group conducted a cross-sectional case-control study involving 190 patients with MEN-1 syndrome, demonstrating a relative risk of breast cancer of 2.83 $(\mathrm{p}<0.001)$ in this population, with an incidence ratio of 2.14 (95\% CI, 1.18 to 3.86 ) and an earlier median age of diagnosis (45 years, compared with 61.2 years in the global Dutch population). ${ }^{13}$ These results were corroborated by a study of three independent cohorts (USA, Tasmania and France), which comprised a total of 675 patients with MEN1, also demonstrating, compared with their respective national cancer registries, increased risk and incidence ratios, as well as an earlier average age of diagnosis (51 years). ${ }^{14}$ The authors of these studies found that the majority of breast tumours in these patients were luminal type and raised the possibility that early breast cancer screening might be needed in patients with MEN-1 syndrome.

We present the case of a patient whose diagnosis of MEN-1 syndrome was made during staging for a breast tumour. In addition to the surgery performed on this tumour, the patient underwent resection of a lung carcinoid tumour, a neuroendocrine pancreatic tumour and parathyroid adenomas.

\section{CASE PRESENTATION}

We describe the case of a female patient, 47 years old, born in Brazil and living in Portugal for 12 years, with a personal history of vaginal uterine myomectomy in 2012, polycystic ovary disease and medicated with an anticonception pill, and a family history of unspecified thyroid pathology (sister) and unspecified parathyroid pathology (father), without other relevant family history.

The patient underwent mammography in December 2013 after self-detection of a nodule in the left upper-inner breast quadrant, which documented a suspected nodular lesion in that location. She was referred to a Breast Surgery consultation, presenting a palpable firm lesion in the left upper-inner quadrant, about $3 \times 2 \mathrm{~cm}$, with irregular borders and hard consistency, adherent to the deeper planes-without palpable adenopathies and without other relevant findings. In February 2014, an ultrasound-guided biopsy of the referred lesion was performed, which revealed invasive ductal carcinoma (no special type (NST)), grade 2 of histological malignancy, with the following molecular profile: oestrogen receptors, 100\%; progesterone receptors, 100\%; Ki67, >20\%; p53 negative; and the absence of amplification of the HER2 gene (luminal B). A breast MRI was performed for locoregional staging, which confirmed, in T1 weighting, the presence of a lesion with irregular nodular morphology, with heterogeneous contrast uptake, $30 \times 25 \mathrm{~mm}$ in dimension, without evidence of multifocality, multicentricity or nodal disease. No pathological changes were detected in the contralateral breast by any of these imaging tests (figures 1-3).

After discussion of the case by a multidisciplinary team, it was decided to perform a sentinel lymph node biopsy followed by

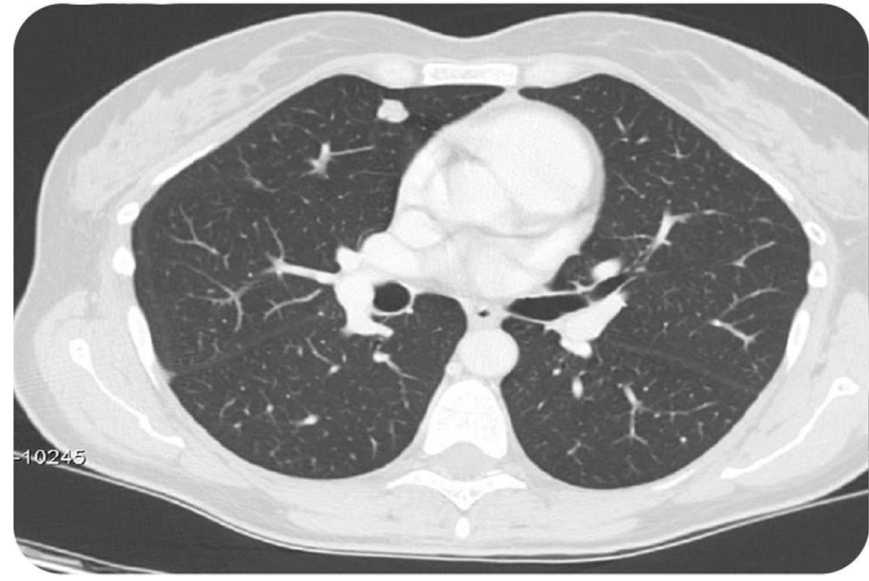

Figure 4 Thoracic CT with intravenous contrast $-10 \mathrm{~mm}$ nodular lesion in the upper lobe of the right lung.

neoadjuvant chemotherapy. Sentinel node biopsy was performed in March 2014, which did not document the presence of neoplastic tissue.

Clinical staging was completed with thoraco-abdominal-pelvic CT scan with administration of oral and intravenous contrast in April 2014, which identified in the upper lobe of the right lung a $10 \mathrm{~mm}$ non-calcified hypodense solid nodule (of undetermined nature by this examination), heterogeneous uterus and increased dimensions of both ovaries, with hypodense parenchyma. There was no evidence of nodal or metastatic disease. This study was complemented with abdominal and pelvic ultrasound (suprapubic and endocavitary), which revealed three myomatous formations in the uterus (two subserous and one submucosal) and ovaries with increased dimensions (with $4.1 \mathrm{~cm}$ of greater axis on the right and $3.6 \mathrm{~cm}$ of greater axis on the left), with several millimetric follicles, without other major changes. It should be noted that at this time none of the tests revealed pathological changes in the pancreas.

Regarding the nodule of the upper lobe of the right lung identified by CT imaging, a CT-guided needle aspiration biopsy was performed, whose histopathological analysis revealed aspects compatible with a carcinoid tumour (positive for thyroid transcription factor 1, chromogranin A, synaptophysin and CD56) (figure 4).

Laboratory evaluation showed no elevation of tumour markers (carcinoembryonic antigen (CEA) and cancer antigen (CA) 15-3)), but demonstrated a persistent elevation in calcium $(12.3 \mathrm{mg} / \mathrm{dL}$; normal reference value: $9-10.5 \mathrm{mg} / \mathrm{dL})$; the parathyroid hormone (PTH) level was $478 \mathrm{pg} / \mathrm{mL}$ (normal reference value: $14-72 \mathrm{pg} / \mathrm{mL}$ ), without increased vitamin $\mathrm{D}$ value and without hypoalbuminaemia. Of the remaining laboratory results, we highlight the following: serum phosphorus, $2.1 \mathrm{mg} / \mathrm{dL}$; thyroid-stimulating hormone, 0.97; fT3 (free tri-iodothyronine) and fT4 (free thyroxine) within normal values; negative antithyroid antibodies; and calcitonin, prolactin, adrenocorticotropic hormone, serum cortisol, urinary cortisol, insulin-like growth factor 1 (IGF-1) and urinary catecholamine assay all within normal reference values.

A cervical ultrasound was requested, which showed, below the left lobe of the thyroid, the presence of a $23 \times 12 \mathrm{~mm}$ hypoechoic solid oval lesion with a probable origin in the parathyroid gland. This study was complemented with parathyroid scintigraphy, which confirmed the suspicion of left parathyroid adenoma (figure 5). 


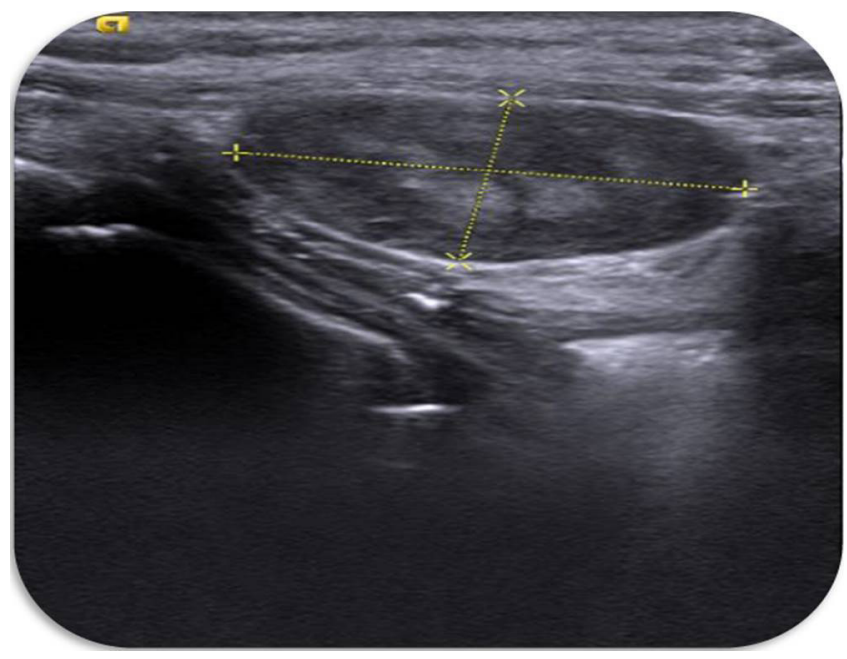

Figure 5 Cervical ultrasound-hypoechogenic solid oval lesion inferior to the left thyroid lobe, $23 \times 12 \mathrm{~mm}$.

Thus, the patient had three distinct pathological entitiesinvasive carcinoma of the left breast (cT3N0M0), carcinoid tumour of the right lung and primary hyperparathyroidism. After completing six cycles of neoadjuvant chemotherapy (four cycles of adriamycin and two cycles of paclitaxel; completed in July 2014), with an imagiological response greater than 50\% in breast MRI, she underwent tumorectomy+contralateral mammoplasty in August 2014. The histopathological analysis of the tumorectomy specimen confirmed a ductal invasive carcinoma of the breast, with $1 \mathrm{~cm}$ major axis, with tumour-free surgical margins. Adjuvant radiotherapy was performed to the left breast with a boost over the tumour bed (total of 60 Gy in 30 fractions), and the patient was given maintenance therapy with tamoxifen (figure 6).

In October 2014, an atypical resection of the right lung was performed, whose histopathological analysis of the surgical specimen confirmed a typical carcinoid tumour, with a Ki67 of 2\% (figure 7).

A left lower parathyroidectomy was performed in November 2014 , with the analysis to the surgical specimen confirming the suspicion of parathyroid adenoma (figure 8).

There were no postoperative complications related to the surgeries described above. The patient was followed up in a General Surgery, Oncology and Endocrinology consultation, revealing improved levels of calcium and PTH.

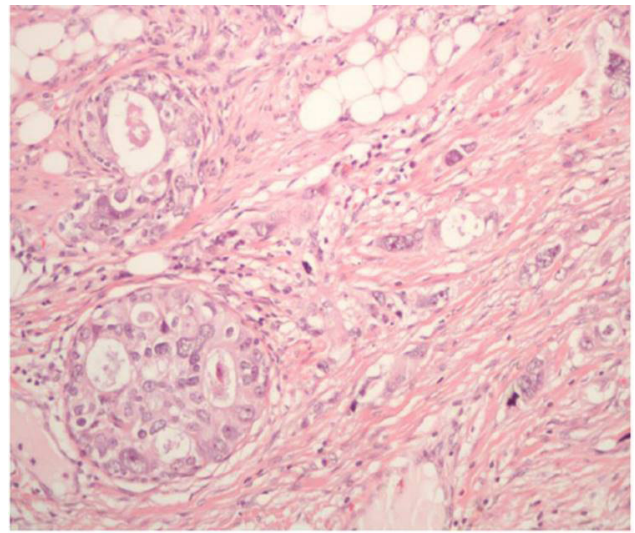

Figure 6 Ductal carcinoma 'in situ' with cribriform pattern and invasive carcinoma NST (no special type) (H\&E, 200x).
In 2016, a follow-up CT scan detected a $1.6 \times 1.3 \mathrm{~cm}$ biloculated cystic formation in the pancreatic tail, with peripheral contrast uptake (figure 9). A laparoscopic enucleation of the lesion was performed, without complications. The histopathological analysis of the specimen documented a NET (positivity for chromogranin and synaptophysin) of $1.9 \mathrm{~cm}$ of major axis, grade 1 of malignancy, with Ki67 below 2\%, without images of lymphoangioinvasion and with free surgical margins.

Because of the presentation of multiple neoplastic lesions whose set fit the spectrum of the MEN-1 syndrome in this patient, she was referred to a Medical Genetics consultation, and a genetic study was carried out-an analysis of a peripheral blood DNA sample was performed by 'new-generation' sequencing (next-generation sequencing) using the TruSight Cancer Gene Set methodology. Molecular analysis of the MEN1 and HRPT2 genes was performed; research was also carried out on major deletions/duplications of the MEN1 gene using the multiple ligation-dependent probe amplification technique. A germline heterozygote mutation was detected, c.249_252delGTCT, in exon 2 of the MEN1 gene, which encodes a truncated protein (p.Ile85SerfsX33) - this mutation consists of a 4 bp deletion starting at codon 85; the in silico analysis carried out with the Mutation Taster software classified this variant as causing disease, and the Human Genome Database classifies it as pathogenic; this mutation is one of the most frequent in families with $\mathrm{MEN}-1^{15}$; this result was compatible with the diagnosis of MEN-1 syndrome.

The patient maintained follow-up with General Surgery, Oncology and Endocrinology. No tumour recurrence or metastatic disease of breast carcinoma, lung carcinoid tumour or NET of the tail of the pancreas was observed during the follow-up period (6 and 4 years, respectively).

Due to recurrence of primary hyperparathyroidism associated with a hypoechoic solid nodule of $12 \times 10 \mathrm{~mm}$ in the right lobe of the thyroid (with aspiration cytology compatible with follicular tumour), the patient underwent another surgical procedure in May 2018-right thyroid lobectomy+right lower parathyroidectomy, revealing intraparenchymal parathyroid with hyperplasia/adenoma (corresponding to the nodule described in cervical ultrasound) and hyperplasia of the right lower parathyroid in the surgical specimen, without thyroid neoplasia tissue (figure 10).

The patient has kept follow-up by the previously mentioned specialties, presenting at the moment without evidence of recurrent or de novo neoplastic disease. There were no complications related to any of the surgeries performed. A normalisation of the levels of calcium and PTH has been observed after the last surgery performed, and no elevation of tumour markers (CEA, CA 19.9 and CA 15-3) or other pathological parameters has been documented to date.

\section{DIFFERENTIAL DIAGNOSIS}

Considering each pathological entity separately, one could take into consideration multiple diagnoses.

For the breast tumour, breast cancer, traumatic fat necrosis, radial scar and hyalinised fibroadenoma were the most probable diagnoses. The breast imaging that was performed in this case was suggestive of breast cancer, which later was confirmed through an ultrasound biopsy that revealed a ductal carcinoma; despite this, the images obtained could also be compatible with the diagnoses described above.

As for the lung carcinoid tumour, the differential diagnosis is the same as for a solitary pulmonary nodule, with breast 


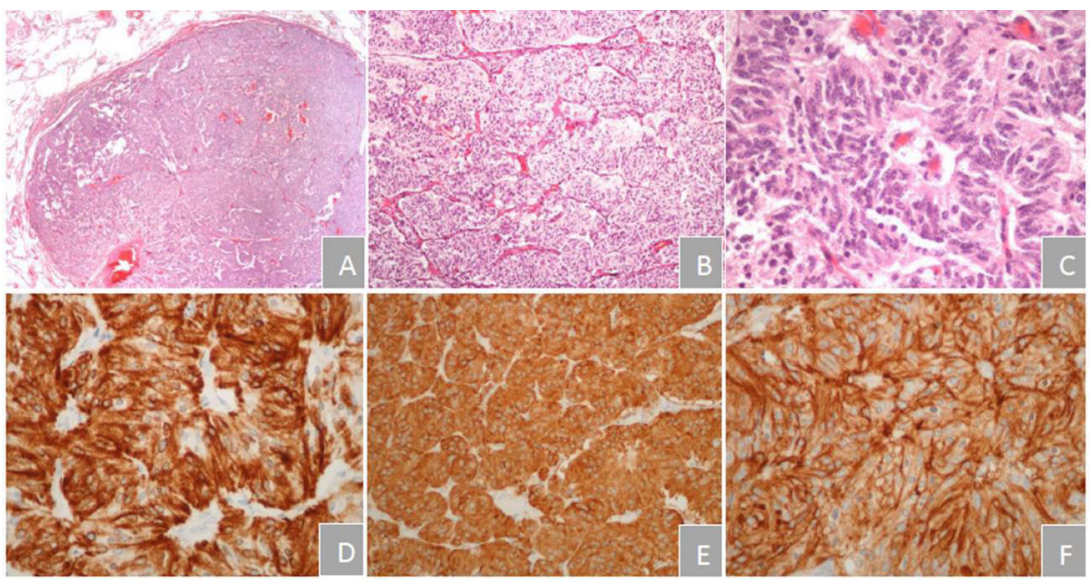

Figure 7 Pulmonary tumour ( $\mathrm{A}, \mathrm{H} \& \mathrm{E}, 20 \mathrm{x})$ with an organoid pattern $(\mathrm{B}, \mathrm{H} \& \mathrm{E} 100 \mathrm{x})$ composed of cells with vast eosinophilic cytoplasm and roundto-oval nuclei with 'salt and pepper' chromatin; no necrosis was found, and the mitotic count was 2 mitoses/10 high-power field; the neoplastic cells are positive to neuroendocrine markers: (D) CK8/18, 400x, (E) synaptophysin, 200x and (F) CD56, 400x.

carcinoma metastasis being the most probable, taking into account the primary disease presented by the patient. A bronchogenic carcinoma, a lymphoma or other primary tumours of the lung could also be taken into consideration.

Considering the pancreatic tumour, the CT scan images that documented the lesion in the pancreatic tail were suggestive of pancreatic NET, but one could also consider the diagnoses of pancreatic adenocarcinoma or pancreatic cystic neoplasm (serous cystadenoma, mucous cystadenoma, solid pseudopapillary neoplasm).

Taking into account the persistent raised calcium and PTH values shown on laboratory analysis on this patient, one could consider the three main causes of hyperparathyroidismprimary hyperparathyroidism, familial benign hyperparathyroidism and humoral hypercalcaemia of malignancy. The imaging findings and later pathological confirmation of a parathyroid adenoma confirmed the probable diagnosis of primary hyperparathyroidism.

Nevertheless, the multiple neoplastic lesions that were diagnosed in this patient throughout the work-up of a breast tumour, excluding the breast tumour per se, as a whole were compatible

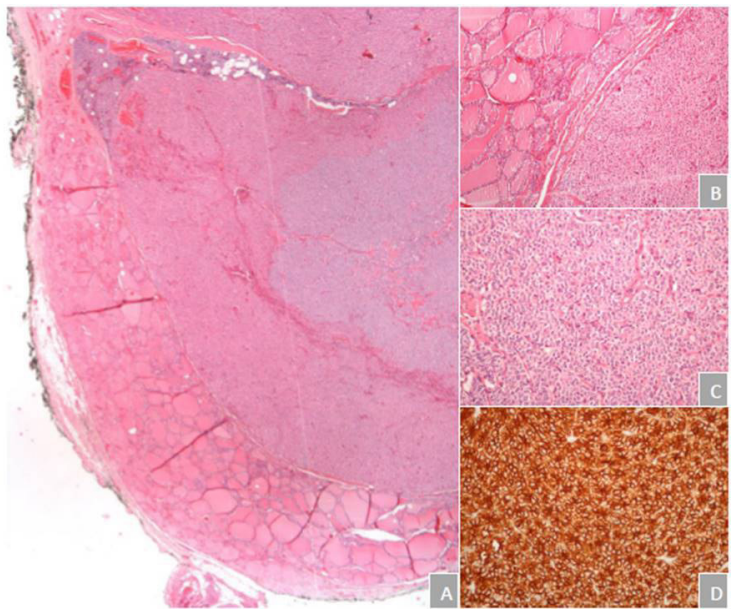

Figure 8 A thyroid nodule $(A, H \& E, 20 x$; interface between thyroid parenchyma and the nodule- $B, H \& E, 100 x)$ that is compatible with hyperplastic/adenomatous parathyroid tissue $(C, H \& E$ and $D$, parathyroid hormone, 200x). with MEN syndrome, which put this diagnosis as the most probable one.

\section{TREATMENT}

The line of treatment of the multiple neoplastic lesions in this patient was namely surgical, with the exception of the breast carcinoma, the treatment of which comprised systemic therapy with chemoradiotherapy and tamoxifen.

After the established diagnosis of a breast ductal carcinoma cT3N0M0, in a multidisciplinary team consultation it was decided to perform a sentinel lymph node biopsy followed by neoadjuvant chemotherapy. Sentinel node biopsy was performed in March 2014, which did not document the presence of neoplastic tissue.

The patient then underwent six cycles of neoadjuvant chemotherapy (four cycles of adriamycin and two cycles of paclitaxel; completed in July 2014), with an imagiological response greater than 50\% in breast MRI. In August 2014, tumorectomy+contralateral mammoplasty was performed. Adjuvant radiotherapy was performed to the left breast with a boost over the tumour bed (total of $60 \mathrm{~Gy}$ in 30 fractions), and the patient was given maintenance therapy with tamoxifen.

In October 2014, an atypical resection of the right lung was performed. Later that year, in November 2014, the patient

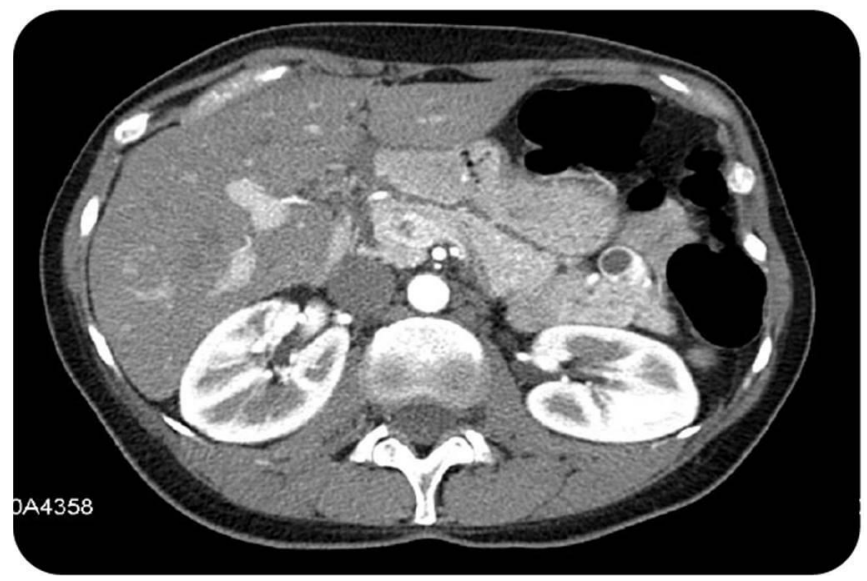

Figure 9 Abdominal CT with oral and intravenous contrastneuroendocrine tumour of the pancreatic tail. 


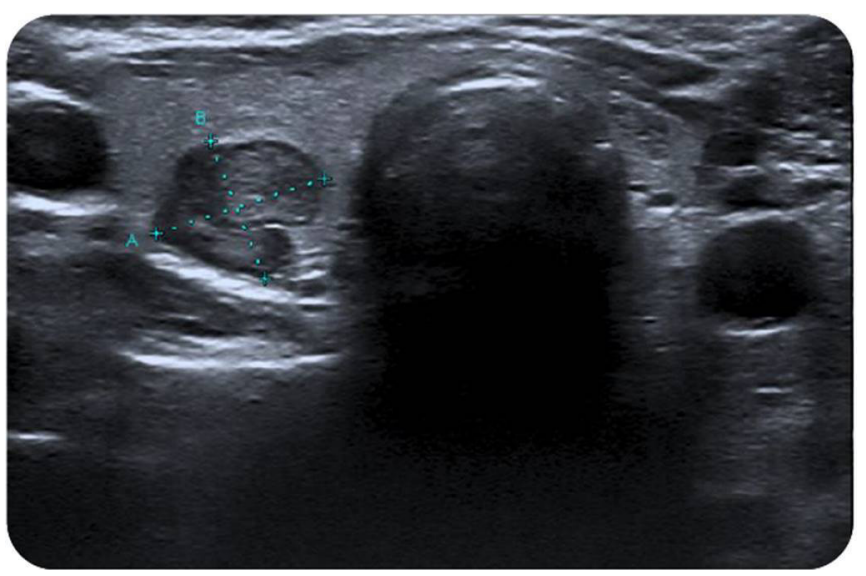

Figure 10 Cervical ultrasound — solid hypoechogenic lesion, slightly heterogeneous and vascularised, with dimensions of $12 \times 10 \mathrm{~mm}$, in the posterior aspect of the right lobe of the thyroid glandintraparenchymal parathyroid adenoma.

underwent a left lower parathyroidectomy. In May 2018, due to recurrence of primary hyperparathyroidism associated with a hypoechoic solid nodule of $12 \times 10 \mathrm{~mm}$ in the right lobe of the thyroid (with aspiration cytology compatible with follicular tumour), the patient underwent right thyroid lobectomy+right lower parathyroidectomy.

As for the pancreatic NET, a laparoscopic enucleation was performed in 2016

\section{OUTCOME AND FOLLOW-UP}

The patient maintained follow-up with General Surgery, Oncology and Endocrinology, presenting at the moment without evidence of recurrent or de novo neoplastic disease. There were no complications related to any of the surgeries performed. A normalisation of the levels of calcium and PTH has been observed after the last surgery performed, and no elevation of tumour markers (CEA, CA 19.9 and CA 15-3) or other pathological parameters has been documented to date.

\section{DISCUSSION}

The MEN-1 gene consists of 10 exons, with a genomic sequence of $7.2 \mathrm{~kb}$, encoding the menin protein, composed of 610 amino acids and without homologies with other proteins. This protein has relationships with multiple other proteins (JunD, MLL, NF-KB1, GAST, WDR5 and SMAD3, among others) with important functions in the cell cycle; the loss of one or more of these interactions can contribute to tumorigenesis by multiple mechanisms. $^{16}$

Through its functions in the regulation of gene transcription and control of the cell cycle, the menin protein exerts a tumour suppressive effect; it has been demonstrated how MEN-1 syndrome, through inactivating mutations, leads to a predisposition for the development of tumour cells.

Multiple recent studies have shown how, at the cellular level, MEN-1 syndrome can lead to tumorigenesis in mammary epithelial cells ${ }^{8-11}$; these results were applied to studies of subpopulations of patients with MEN-1 syndrome, which demonstrated a more frequent and earlier appearance of breast carcinoma in these patients in comparison with the global population. ${ }^{13} 14$ The authors of these latest studies conclude that patients with MEN-1 syndrome are at an increased risk of developing breast cancer (especially luminal carcinomas) and suggest the age of 40 years for the start of screening in this subpopulation.
The clinical case we present, despite being punctual, meets the lines of evidence mentioned above - the patient developed an invasive breast carcinoma at a relatively early age (47 years), and its molecular profile indicated that it was a luminal type. The diagnosis of MEN-1 syndrome in this clinical case was obtained after finding multiple neoplastic lesions during the initial stage and subsequent follow-up of a breast tumour-the diagnosis of invasive ductal carcinoma comes first, with the carcinoid tumour of the lung and the primary hyperparathyroidism being diagnosed during staging examinations; the clinical, laboratory and imaging follow-up after the first surgeries performed allowed the early diagnosis and treatment of the pancreatic NET that the patient developed. Finding a set of neoplastic lesions that, with the exception of breast carcinoma, coincided with the expected spectrum in patients with MEN-1 syndrome, the patient was referred to a Genetics consultation, and the necessary tests were performed for the diagnosis of her genetic disease-MEN-1 syndrome.

It is important to mention that, within the most frequent lesions within MEN-1 syndrome, the patient had primary hyperparathyroidism and a pancreaticNET, but had no evidence of pituitary lesions (confirmed by brain CT; also there were never increased levels of prolactin or IGF-1 in laboratory tests). However, the patient had a carcinoid tumour of the lung and breast carcinoma, as already described.

This case is yet another example that meets the growing amount of evidence that links MEN-1 syndrome with breast cancer. The finding of this relationship and the earlier appearance of breast tumours in these patients should raise the following question-shouldn't the start of breast cancer screening be carried out earlier in this subpopulation? It would be useful to try to reproduce the results of the population studies mentioned above in other subpopulations of patients with MEN-1 syndrome to further corroborate them and consolidate the concept of this relationship. Finally, the knowledge that mutations in the MEN-1 gene can lead to tumorigenesis of breast cells, through the previously mentioned mechanisms, may be the source for new research that leads to the development of new therapeutic agents in the treatment of breast cancer.

\section{Patient's perspective}

I am glad to know that my case is being submitted for publishing, and I hope this raises awareness for type 1 multiple endocrine neoplasia syndrome. I am delighted to be of help for doctors and to have the opportunity to contribute to science.

\section{Learning points}

- There is growing evidence that links mutations in MEN-1 gene and breast oncogenesis

- Population studies in patients with type 1 multiple endocrine neoplasia (MEN-1) syndrome documented a more frequent and earlier appearance of breast carcinoma (namely, luminal type) in these patients in comparison with the global population

- Patients with MEN-1 should be considered for earlier screening for breast cancer

Contributors BCM wrote this manuscript, conducted the literature review and compiled the images related to imagiology examinations, as well as gathered relevant data from this case for the report. The idea for the current paper was by given NA, who was in charge of the Breast Surgery Unit who took responsibility 
for the presentation of this case to a multidisciplinary team and performed the described breast surgery. ACQ was responsible for the compilation and description of the pathology-related images that we present in this case report. She also contributed to the revision of this paper. JC and NA provided author insight on the elaboration of this paper and made the final revisions before submitting the paper. JC is also the Head of the Surgery Department in which the patient was treated.

Funding The authors have not declared a specific grant for this research from any funding agency in the public, commercial or not-for-profit sectors.

Competing interests None declared.

Patient consent for publication Obtained.

Provenance and peer review Not commissioned; externally peer reviewed.

Open access This is an open access article distributed in accordance with the Creative Commons Attribution Non Commercial (CC BY-NC 4.0) license, which permits others to distribute, remix, adapt, build upon this work non-commercially, and license their derivative works on different terms, provided the original work is properly cited and the use is non-commercial. See: http://creativecommons.org/ licenses/by-nc/4.0/.

ORCID iD

Bernardo Conde Maria http://orcid.org/0000-0002-9814-4787

\section{REFERENCES}

1 Busygina V, Bale AE. Multiple endocrine neoplasia type 1 (MEN1) as a cancer predisposition syndrome: clues into the mechanisms of MEN1-related carcinogenesis. Yale J Biol Med 2006;79:105-14.

2 Thakker RV, Newey PJ, Walls GV, Rajesh V, et al. Clinical practice guidelines for multiple endocrine neoplasia type 1 (MEN1). J Clin Endocrinol Metab 2012;97:2990-3011.

3 Hughes CM, Rozenblatt-Rosen 0, Milne TA, et al. Menin associates with a trithorax family histone methyltransferase complex and with the HOXC8 locus. Mol Cell 2004; 13:587-97.
4 Yokoyama A, Wang Z, Wysocka J, et al. Leukemia proto-oncoprotein MLL forms a SET1-like histone methyltransferase complex with menin to regulate Hox gene expression. Mol Cell Biol 2004;24:5639-49.

5 Milne TA, Hughes CM, Lloyd R, et al. Menin and MLL cooperatively regulate expression of cyclin-dependent kinase inhibitors. Proc Natl Acad Sci U SA 2005; 102:749-54.

6 Busygina V, Kottemann MC, Scott KL, et al. Multiple endocrine neoplasia type 1 interacts with forkhead transcription factor CHES1 in DNA damage response. Cancer Res 2006;66:8397-403

7 Jeong YJ, Oh HK, Bong JG. Multiple endocrine neoplasia type 1 associated with breast cancer: a case report and review of the literature. Oncol Lett 2014;8:230-4.

8 Seigne C, Auret M, Treilleux I, et al. High incidence of mammary intraepithelial neoplasia development in Men1-disrupted murine mammary glands. J Pathol 2013;229:546-58.

9 Imachi H, Murao K, Dobashi H, Dobashi H, et al. Menin, a product of the MENI gene, binds to estrogen receptor to enhance its activity in breast cancer cells: possibility of a novel predictive factor for tamoxifen resistance. Breast Cancer Res Treat 2010;122:395-407.

10 Dreijerink KMA, Mulder KW, Winkler GS, et al. Menin links estrogen receptor activation to histone H3K4 trimethylation. Cancer Res 2006;66:4929-35.

11 Amiry N, Kong X, Muniraj N, et al. Trefoil factor- 1 (TFF1) enhances oncogenicity of mammary carcinoma cells. Endocrinology 2009;150:4473-83.

12 Poulsom R, Hanby AM, Lalani EN, et al. Intestinal trefoil factor (TFF 3) and pS2 (TFF 1), but not spasmolytic polypeptide (TFF 2) mRNAs are co-expressed in normal, hyperplastic, and neoplastic human breast epithelium. J Pathol 1997;183:30-8

13 van Leeuwaarde RS, Dreijerink KM, Ausems MG, et al. MEN1-Dependent breast cancer: indication for early screening? results from the Dutch MEN1 Study Group. J Clin Endocrinol Metab 2017;102:2083-90.

14 Dreijerink KMA, Goudet P, Burgess JR, et al. Breast-Cancer predisposition in multiple endocrine neoplasia type 1. N Engl J Med 2014;371:583-4.

15 Lemos MC, Thakker RV. Multiple endocrine neoplasia type 1 (MEN1): analysis of 1336 mutations reported in the first decade following identification of the gene. Hum Mutat 2008;29:22-32

16 Romei C, Pardi E, Cetani F, et al. Genetic and clinical features of multiple endocrine neoplasia types 1 and 2. J Oncol 2012:2012:1-15.

Copyright 2020 BMJ Publishing Group. All rights reserved. For permission to reuse any of this content visit

https://www.bmj.com/company/products-services/rights-and-licensing/permissions/

BMJ Case Report Fellows may re-use this article for personal use and teaching without any further permission.

Become a Fellow of BMJ Case Reports today and you can:

- Submit as many cases as you like

- Enjoy fast sympathetic peer review and rapid publication of accepted articles

- Access all the published articles

Re-use any of the published material for personal use and teaching without further permission

Customer Service

If you have any further queries about your subscription, please contact our customer services team on +44 (0) 2071111105 or via email at support@bmj.com.

Visit casereports.bmj.com for more articles like this and to become a Fellow 